International Journal of

Soft Computing And Software Engineering (JSCSE)

e-ISSN: 2251-7545

Vol.2,No.10, 2012

Published online: Oct 25, 2012

DOI: 10.7321/jscse.v2.n10.1

\title{
Towards a Curriculum Design Maturity Model
}

\author{
${ }^{1}$ Thong Chee Ling, ${ }^{* 2}$ Yusmadi Yah Jusoh, ${ }^{3}$ Rusli Abdullah, ${ }^{4}$ Nor Hayati Alwi \\ ${ }^{1,2,3}$ Faculty of Computer Science and Information Technology, Universiti Putra Malaysia, \\ Serdang, Selangor, Malaysia \\ ${ }^{4}$ Faculty of Educational Studies, Universiti Putra Malaysia, Serdang, Selangor, \\ Malaysia \\ Email:1mailto:chloethong11@yahoo.com,2yusmadi@fsktm.upm.edu.my, \\ 3rusli@fsktm.upm.edu.my, ${ }^{4}$ nalwi@putra.upm.edu.my
}

Abstract. The Capability Maturity Model (CMM) is used in the software industry to improve design process as well as product quality. Likewise, CMM is also used in the education sector for a similar purpose. This paper presents, in particular, a proposed maturity model for curriculum design for Institutions of Higher Learning in Malaysia. The Curriculum Design Maturity Model ONE (CDMM-1) is specifically aimed at guiding curriculum designers in producing quality curricula according to programme specifications. In this study, CDMM-1, which is derived from the proposed maturity model, has both process and product components. However, this paper only focuses on the product quality aspect.

Keywords: Capability Maturity Model, Curriculum Design, Curriculum Designer, Quality Curriculum, Institution of Higher Learning

* Corresponding Author:

Yusmadi Yah Jusoh

Faculty of Computer Science and Information Technology, Universiti Putra Malaysia,

Serdang, Selangor, Malaysia

Email: ${ }^{1}$ mailto:chloethong11@yahoo.com

\section{Introduction}

Curriculum quality is much related to the success of an educational institution [1]. Hence, educational institutions should pay careful attention to their curriculum design as it functions as a framework in meeting their institutional goals and missions. The development of a curriculum and its quality assessment can be rather complex and time consuming. However, despite much effort spent in designing them, uncertainty remains over the quality of the resulting curriculum [2]. Through literature review, we know that the design process plays an important role in producing quality products [3]. Fortunately, product quality can be determined independently, irrespective of the process used to create it.

This study has significant potential in helping curriculum designers produce quality curricula using a proposed maturity model. This paper aims to construct a maturity model to be used as a guide for curriculum designers in designing quality curricula for institutions of higher learning (IHLs). The Capability Maturity Model (CMM) is adopted as process improvement model for optimizing the quality of the product (curriculum). According to Jalote [4], CMMs could be a means to overcome the lack of quality standards in the education sector.

One of the greatest challenges faced by curriculum designers today is producing a quality curriculum for higher education since quality assurance in this sector is a relatively recent development in most ASEAN countries [16]. Two decades ago, researchers discovered several challenges encountered by curriculum designers [19], among which are the lack of knowledge of educational 
International Journal of

Soft Computing And Software Engineering (JSCSE)

e-ISSN: 2251-7545

Vol.2,No.10, 2012

剿SSE

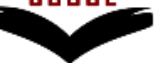

DOI: 10.7321/jscse.v2.n10.1

Published online: Oct 25, 2012

literature on curriculum development and course design, and the lack of skills in designing responsive courses, authentic assessments and effective delivery strategies. The question is whether those challenges from 1991 are relevant today, particularly at the Institutions of Higher Learning in Malaysia. A common challenge faced by Malaysia's higher education sector is the ineffective academic curricula and materials (mismatch between curricula and working requirements; irrelevant curricula). Therefore, teaching-learning, an aspect of quality assurance in higher education particularly for curriculum design and maintenance, has been identified as critical to its development in Malaysia [23].

The remaining sections of this paper are organized as follows. In Section 2, the research background is presented and reviewed. Section 3 explains the methodology. Next, the structure of the curriculum design maturity model is presented in Section 4. In Section 5, we discuss our insights into the study and finally, Section 6 concludes the paper.

\section{Background}

\subsection{Related Work}

To produce quality software products, it is the development process that is important. Similarly, to produce quality curricula, it is the design process that is crucial. Curriculum design and software development share several similarities. Both involve complex activities and development life cycles, and both emphasize design quality. The success of both domains depends on good structures and the use of best practices, i.e. processes that help us structure and do things right [3].

There are five processes in CMM, with each process broken up into practices that are assessed at every level based on given assessment criteria. The key product quality attribute (KPQA) used in this study is programme coherence (hereinafter referred to as curriculum alignment). The maturity level used for this study is Level 2 as it is believed that most organizations have achieved Level 2 of CMM.

Table 1. Capability Maturity Model (CMM) [6]

\begin{tabular}{ll}
\hline Maturity Level & Brief Description \\
\hline Initial & $\begin{array}{l}\text { The software process is characterized as ad hoc, and occasionally even } \\
\text { chaotic. Few processes are defined, and success depends on individual } \\
\text { effort and heroics. }\end{array}$ \\
Basic project management processes are established to track cost, \\
schedule and functionality. The necessary process discipline is in place to \\
repeat earlier successes in projects with similar applications. \\
The software processes for both management and engineering activities \\
are documented, standardized and integrated into a standard software \\
process for the organization. All projects use an approved, tailored \\
version of the organization's standard software process for developing \\
and maintaining software. \\
Detailed measurements of the software process and product quality are \\
collected. Both the software process and products are quantitatively \\
understood and controlled. \\
Continuous process improvement is enabled by quantitative feedback \\
from the process and from piloting innovative ideas and technologies.
\end{tabular}

There has been quite a history in the application of CMM in education. Many maturity models have been constructed based on CMM to address the absence of quality standards in education. Some of these are process improvement models used by higher education to support online course design and curriculum design for Information Systems education, while others are process improvement models 
International Journal of

Soft Computing And Software Engineering (JSCSE)

e-ISSN: 2251-7545

Vol.2,No.10, 2012

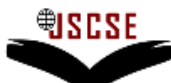

Published online: Oct 25, 2012

DOI: 10.7321/jscse.v2.n10.1

for other areas such as e-learning [5][8][9]. The two maturity models referred to in this study are the online course design maturity model (OCDMM) introduced by Neuhauser [5] and the curriculum redesign model with CMM introduced by Dennis Drinka and Minnie [9]. Despite the numerous maturity models constructed to support and improve quality design processes, literature review has revealed a lack of maturity models that provide guidance to curriculum designers in designing quality curricula. As a result, the time and effort required for this task will remain as challenging factors to curriculum designers for IHLs in Malaysia [2].

\subsection{Product Quality}

Product quality is difficult to quantify as it is an 'elusive' concept [12]. Likewise, the quality of a curriculum is difficult to define in quantitative terms. If defined, it is usually vague and difficult to measure [13]. In addition, the definition of quality is contextual; users of software products may place greater value on certain quality attributes in one context than another.

Quality is defined by international organisations as follows: "Quality comprises all characteristics and significant features of a product or an activity that relate to the satisfying of given requirements" (German Industry Standard DIN 55350 Part 11).

For the purpose this paper, quality is defined as the state in which a curriculum meets the given requirements stipulated in programme standards, resulting in an outcome that supports national goals for education. In this paper, wherever the term "product" appears in the context of software engineering education, it can also be taken to mean "curriculum".

In Malaysia, the national goals for education, as determined by the Ministry of Higher Education (MOHE), are stated in the National Higher Education Strategic Plan. There are four distinct phases with four strategic thrusts in this plan. It contains the critical implementation mechanism and schedule. This action plan is further divided into three parts, the second of which is the critical agenda. In total, there are 23 critical agenda projects, one of which is quality assurance. In Phase II (2011-2015) of the plan, Institutions of Higher Learning (IHLs), particularly private IHLs, are expected to place emphasis on improving the quality and variety of programmes, which is a key item [17]. This is because the quality of programmes has become critical to the MOHE.

The principal guides to the body of knowledge for software engineering are SWEBOK (Software Engineering Body of Knowledge) and SEEK (Software Engineering Education Body of Knowledge). One of the main objectives of these guides is to identify and describe generally acceptable software engineering knowledge. Although the two bodies of knowledge are distinct, they are closely related in terms of scope [21]. SWEBOK or SEEK can also be adopted as a foundation for curriculum development in Malaysia although it is specific to the U.S. style of education [22]. Many believe that focusing on a few important areas of content to bring students to a level of mastery is a better strategy than a curriculum that attempts to cover a wide range of contents and is, therefore, necessarily shallow in expectations for student mastery [24]. Porter and colleagues highlighted in his article written in 2007, that, "... if focused on the wrong content, could have a disastrous result... focused on the right content, may have a positive result" (p.29).

In Malaysia, a document entitled, "Programme Standards: Computing" (PS) is used as a guide that describes the characteristics of various programmes in Computing disciplines, namely Computer Science (CS), Information Technology (IT), Software Engineering (SE) and Information Systems (IS). This study will only focus on SE. The PS makes reference to documents produced by The Joint Task Force for Computing Curricula, which is a cooperative project of The Association for Computing Machinery (ACM), The Association for Information Systems (AIS) and The Computer Society (IEEECS).

The PS states that, “...the purpose of these programme standards is to provide guidelines in relation to the development and context of programmes in the identified fields. It is of paramount importance that this document be read with other quality assurance documents and policies by the Malaysian Qualifications Agency and related agencies. These include but are not limited to The Malaysian 
International Journal of

Soft Computing And Software Engineering (JSCSE)

e-ISSN: 2251-7545

Vol.2,No.10, 2012

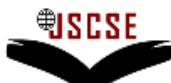

Published online: Oct 25, 2012

Qualification Framework (MQF), The Code of Practice for Programme Accreditation (COPPA), The Code of Practice for Institutional Audit (COPIA), and The Relevant Guidelines to Good Practices (GGP)" (Programme Standards: Computing, p.4)

Within the Malaysian context, it is believed that using the said guidelines and quality assurance documents in designing curricula would result in quality curriculum designs. A software developer may eventually produce good software anyway, as the process by which the quality of the software is developed is not directly visible in the quality of the end product [4]. However, curriculum designers can indirectly influence the end product of their work. In this paper, curriculum designers are defined as educators who try to put the key components of a curriculum in some order or rationality during the process of designing a curriculum by using selected curriculum design models. In the following sections, more related work will be discussed.

\subsection{Key Product Quality Attributes (KPQAs)}

Within the PS, learning outcomes of SE programmes are included, being the most commonly used (assessment) criterion [18]. In this paper, the intended learning outcomes (ILOs) are associated with the classification system introduced by Bloom. Bloom's taxonomy is used as a tool to guide curriculum designers in defining course materials, university curricula etc. [20]. According to Bloom in his book written in 1956, "...the taxonomy should be a logical classification system in that every effort should be made to define terms as precisely as possible to use them consistently" (p.6).

The idea behind taxonomy was formed at the time of its development in 1948 when a group of psychologists discovered the difficulties of cooperation and communication in educational evaluation work, and the limitation they found was the absence of a common frame of reference [15]. Taxonomy was then introduced as a classification system to overcome these difficulties. The contribution value of taxonomy in solving these difficulties lies in the fact that it helps make the objectives (learning outcomes) clear and precise.

For example, the ideal situation in designing clear and precise learning outcomes is when learning outcomes are so clearly stated that the authors (curriculum designers) know what they mean and the readers (teachers/students) have a clear idea of what is intended. It is not easy to attain this ideal. This is mainly due to the difficulties in using language to communicate intentions. However, it might be possible to devise a classification system that permits one to know almost exactly what is meant by a particular category. If a classification system is used, then the authors and readers of the learning outcomes would place them in their relevant categories, thereby making the consequences of the learning experience (TLAs) and the evaluation (assessment tasks) relatively clear and precise [15]. In fact, the terminology used in designing learning outcomes must be clear and meaningful. Classifying the educational objectives would help curriculum designers clarify and tighten the "language" of these educational objectives [15].

There are three major parts of a complete taxonomy, which are the cognitive, the affective and the psychomotor domains. The affective domain includes objectives (learning outcomes) that describe changes in interest, attitude and values, as well as the development of appreciation and adequate adjustment. The psychomotor domain is the manipulative or motor-skill area [14]. Of the three domains stated above, curriculum development has mostly taken place in the cognitive domain. This is also the domain of focus in this study.

A taxonomy is further qualified as intellectual behaviors that represent the intended outcomes of the educational process. Bloom's taxonomy of the cognitive domain comprises six levels of intellectual behavior, namely knowledge (K), comprehension (C), application (AP), analysis (AN), synthesis (S) and evaluation (E) [14]. These six levels can be further categorized by learning outcome into lower level learning outcomes and higher level learning outcomes. These learning outcomes would later need to be refined based on each level's key terms. 
International Journal of

Soft Computing And Software Engineering (JSCSE)

e-ISSN: 2251-7545

Vol.2,No.10, 2012

判SCSE

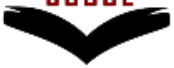

DOI: 10.7321/jscse.v2.n10.1

Published online: Oct 25, 2012

The concept of curriculum alignment is widely accepted as a major principle governing curriculum design. According to Biggs and Tang [26], 'alignment' refers to the state of a learning environment where the key curriculum components, such as teaching and learning activities as well as assessment tasks, are aligned to the intended learning outcomes. The learning environment includes lectures, tutorials, etc. According to Squires [25], alignment is an agreement or a match between two categories. He also pointed out that a robust alignment approach could help develop a good (quality) curriculum.

Curriculum is a term often used by educators. According to Murray [29], the term curriculum is often confused with syllabus. He defines a syllabus as a list of content areas to be assessed and the list is sometimes extended to include a number of objectives and learning activities. In other words, a syllabus is only a subsection of a curriculum. It can be thought of as the curriculum documents.

In software development, for example, the software requirement specifications (SRS) is a document that contains all the necessary requirements for the software project development. Software functionalities and non-functionalities are described in the SRS. Software quality should be evaluated according to its specifications using the conventional interpretation of quality [28]. However, it is rather difficult for a software engineer to craft specifications completely and consistently. Furthermore, some necessary requirements may not be captured in the specifications document (or SRS) [12]. A software product may be assessed as "high quality" according to its specifications even though not all customers' requirements are captured in the final product.

In this study, this document is referred to as the curriculum document and it is likened to the SRS. The scope of curriculum documents in this study is limited only to the key curriculum components, such as the intended learning outcomes (ILOs), TLAs and assessment tasks. This is also one of the limitations defined in this paper that is due to complexity. In addition, the knowledge areas of SE and Bloom's taxonomy are discussed in this paper.

\section{Methodology}

CDMM-1 is a model constructed based on: (1) a review of existing CMMs related to curriculum design; (2) the experience of the authors; and (3) document analysis and literature review. The two models that CDMM-1 is based on are the online course design maturity model (OCDMM) and the curriculum redesign process improvement model for information systems education as proposed by Dennis and Minnie [9] and by Neuhauser [5], respectively. Both these models have their strengths and limitations.

\section{The Curriculum Design Maturity Model (CDMM)}

\subsection{The Structure of CDMM}

The structure of CDMM-1 is derived from a proposed model named Curriculum Design Maturity Model (CDMM), which is the main model constructed based on CMM and focused on the process aspect of curriculum design. CDMM consists of five maturity levels and each level comprises technical and managerial processes. The detailed description of each maturity level is not included in this paper. Table 2 shows the key process areas.

Table 2. The Curriculum Design Maturity Model (CDMM) for a Programme

\begin{tabular}{ll} 
Maturity Level & Key Process Area (KPA) \\
\hline Initial & Initial (Ad Hoc, Chaotic) \\
& Repeatable (Disciplined Process) \\
Repeatable & Technical Processes: \\
& Curriculum Quality Assurance \\
& Managerial Processes: \\
& Curriculum (Re)-Design Tracking
\end{tabular}


International Journal of

Soft Computing And Software Engineering (JSCSE)

e-ISSN: 2251-7545

Vol.2,No.10, 2012

Published online: Oct 25, 2012

DOI: 10.7321/jscse.v2.n10.1

Curriculum (Re)-Design Planning

Requirement Management

Defined

Defined (Standard, Consistent Process)

Technical Processes:

Peer Review

Managerial Processes:

Intergroup coordination

Integrated Curriculum Management

Managed

Managed (Predictable Process)

Managerial Processes:

Curriculum Quality Management

Quantitative Process Management

Optimized

\author{
Optimizing (Continually Improving Process) \\ Technical Processes: \\ Defect Detection \\ Managerial Processes: \\ Process Change Management
}

The technical processes of the repeatable level (Level 2) are the focus of CDMM-1 in this paper. CDMM-1's maturity levels and KPQA are presented in Table 3. The process portion of CDMM-1 is structured into five maturity levels, each of which is associated with key process areas. The product portion of CDMM-1 is inverted.

Table 3. Technical Process of the Repeatable Level

\begin{tabular}{lcc}
\hline Maturity Level & Key Process Area & Goal \\
\hline Repeatable & Curriculum Quality & The curriculum design meets programme \\
& Assurance & specifications \\
\hline
\end{tabular}

Each KPQA has five maturity levels. For the purpose of this paper, only one crucial key process area (KPA) of Level 2 of CDMM-1 is given focus, which is the curriculum quality assurance (refer to Table 4). Level 2 consists of managerial processes and technical processes. Managerial processes are those that significantly affect the way management operates to make decisions and control the project/work during the regular curriculum design life cycle; and technical processes are those that affect the way curriculum designers perform their work, such as conforming to the curriculum structure. This paper only covers a single technical process in Level 2 i.e. curriculum quality assurance.

Table 4. The Technical Process of the Repeatable Level (Level 2) of CDMM-1 and its KPQA

\begin{tabular}{ll} 
Maturity Level & $\begin{array}{l}\text { Key Product Quality Attribute } \\
\text { Curriculum Alignment }\end{array}$ \\
\hline Initial & $\begin{array}{l}\text { Intended learning outcomes (ILOs) lack clarity and are partially } \\
\text { based on Bloom's taxonomy (or other taxonomies) }\end{array}$ \\
Repeatable & $\begin{array}{l}\text { Better clarity of ILOs, and key action verbs are applied; learning } \\
\text { domains are also included to reflect the different aspects of } \\
\text { student learning } \\
\text { (Inline and standardized) }\end{array}$ \\
Befined & $\begin{array}{l}\text { BTs are aligned to ILOs } \\
\text { Measurements of the alignments of TLAs and ATs to ILOs are } \\
\text { Managed }\end{array}$ \\
& made using a template and collected
\end{tabular}


International Journal of

Soft Computing And Software Engineering (JSCSE)

e-ISSN: 2251-7545

Vol.2,No.10, 2012

Published online: Oct 25, 2012

DOI: 10.7321/jscse.v2.n10.1

Optimized Alignments of TLAs and ATs to ILOs continue to improve and student performance at the instructional level are used to gauge the effectiveness of the alignment

In designing new curricula or redesigning existing curricula, the process starts at the Initial level. The reason is that CMM was originally designed for stage-by-stage improvement, with the concept being applied for evolutionary improvements of each process. Process capability is used to predict the most likely results. If a given set of process requirements is satisfied, then we can accurately predict the results. For example, literature shows that a taxonomy table helps improve clarity in communication among curriculum designers by first stating lower-level learning outcomes. If this requirement is fulfilled, then it will move on to the next level. The requirements are developed from benchmarks. These benchmarks are provided in the relevant documents, namely PS, MQF, COPPA, COPPIA and GGP. Other documents may also be used, such as SWEBOK and literature review.

This study focuses on the curriculum redesign process of an academic program in the field of software engineering. Henceforth, the curriculum shall be referred to as the 'programme' and the modules within the programme shall be referred to as 'courses'. A 'programme' is defined as an arrangement of courses that are structured for a specified duration and learning volume to achieve the stated learning outcomes and usually leads to an award of a qualification. A 'module is defined as a unit of learning and teaching, also described as a subject, course or unit in a programme [11]. In this paper, curriculum and programme will be used interchangeably. A brief description of the KPQA of each level will be presented in the following sections.

\subsection{The Structure of CDMM-1}

The key product quality attribute (KPQA) presented in this study is alignment. Several steps need to be taken in designing an aligned curriculum, starting from ensuring clarity of the learning outcomes using Bloom's taxonomy, followed by aligning them to TLAs and assessment tasks using key terms in a proposed taxonomy table.

Level 1- Initial

The clarity of learning outcomes is the lowest at this level. Since the learning outcomes are developed partially based on Bloom's taxonomy, the alignment of learning outcomes with TLAs and assessment tasks are not in place. In fact, there is only partial coverage of knowledge areas in SE disciplines at this level.

Level 2 - Repeatable

In order to illustrate the clarity of learning outcomes, Blooms's taxonomy is used as a tool to defineclear and precise leaning outcomes for each topic covered in the knowledge areas within the SE discipline. There are two process capabilities at this level. Process capability one covers topics within each knowledge area, identifies the cognitive level, and proposes the key terms to be used for each learning outcome in order to improve clarity. Process capability two aligns TLAs and assessment tasks to the learning outcomes based on the key terms used for each component (refer to table 5). The taxonomy is regarded as a useful and effective tool for curriculum design. According to Bloom and his colleagues (1956), if a taxonomy is regarded as a useful and effective tool, then it must be accepted and used by curriculum workers (designers). 
International Journal of

Soft Computing And Software Engineering (JSCSE)

e-ISSN: 2251-7545

Vol.2,No.10, 2012

Published online: Oct 25, 2012

DOI: 10.7321/jscse.v2.n10.1

Table 5. Taxonomy Table with Key Curriculum Components [26]

\begin{tabular}{|c|c|c|}
\hline $\begin{array}{c}\text { LOs } \\
\text { (common) }\end{array}$ & TLAs (possible) & Assessment Tasks (possible) \\
\hline Describe & $\begin{array}{l}\text { Set reading material, lecture, } \\
\text { report on field trip, write essay } \\
\text { Key terms used: } \\
\text { Lecture: talk, explain, clarify }\end{array}$ & $\begin{array}{l}\text { Assignment, essay question, exam } \\
\text { Useful for: } \\
\text { Exam: recall unit of information }\end{array}$ \\
\hline Explain & Tutorial, activity, write essay & $\begin{array}{l}\text { Assignment, essay question, exam, } \\
\text { oral presentation }\end{array}$ \\
\hline Integrate & Project, assignment & Project, assignment \\
\hline Analyze & To be determined & Case study, assignment \\
\hline Apply & Project, case study & Project, case study, experiment \\
\hline Solve problem & PBL, case study & Case study, project, experiment \\
\hline Design, create & Project, poster & Project, experiment, poster \\
\hline Reflect & Reflective diary & $\begin{array}{l}\text { Reflective diary, portfolio, self- } \\
\text { assessment }\end{array}$ \\
\hline Communicate & To be determined & $\begin{array}{l}\text { A range of oral, writing or listening } \\
\text { tasks addressing the ILOs, e.g. } \\
\text { presentation, debate, role play, } \\
\text { reporting, assignment, paraphrasing, } \\
\text { answering questions, etc. }\end{array}$ \\
\hline $\begin{array}{l}\text { Hypothesize } \\
\text { (typical) }\end{array}$ & Experiment, project & To be determined \\
\hline
\end{tabular}

Level 3- Defined

The difference between Level 2 and Level 3 alignments is that Level 3 fully applies Bloom's taxonomy in designing learning outcomes and aligns TLAs and assessment tasks to learning outcomes based on taxonomy table. In fact, the clarity of key terms used in learning outcomes facilitates communication between curriculum designers, using Bloom's taxonomy. There is also full coverage of knowledge areas for related key topics in SE at this level.

Level 4- Managed

Alignment is made possible using taxonomy as an effective tool. Alignment is determined based on the key terms used for the three key curriculum components. At this level, a template is used to gauge the coverage of each knowledge area.

Level 5- Optimized

A continuous improvement process takes place at this level. This level was renamed the 'optimizing' level in early 1988 because the continuous process is considered to be a never-ending improvement journey [27]. The alignment of the three key components needs to go through an instructional process to gauge its success. Student performance indicates the effectiveness of the alignment and the continuous improvement process iteration. 
International Journal of

Soft Computing And Software Engineering (JSCSE)

e-ISSN: 2251-7545

Vol.2,No.10, 2012

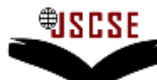

Published online: Oct 25, 2012

DOI: 10.7321/jscse.v2.n10.1

\section{Discussion}

Product quality has always been a somewhat elusive concept that is difficult to quantify. In software engineering, there are a number of tangible attributes, such as the measurement of the line of source codes in a software programme, which is used as an indirect indicator of quality attributes. Assessing curriculum quality in the context of clarity and precision is rather challenging since curriculum quality is dependent on attributes such as the alignment of learning outcomes with TLAs and assessment tasks. It is difficult to define a unified model of curriculum quality that is suitable for all domains and circumstances. This paper presents the preliminary work towards producing a curriculum design maturity model that captures the important attributes of a product. In this study, one KPQA is presented. However, there are other relevant KPQAs that are currently under consideration for inclusion in future work. Further research can be done by investigating other KPQAs that may determine the quality of a curriculum.

\section{Conclusion}

The findings can be utilized for future research in determining curriculum quality. Continuous improvement is needed to ensure that a proposed model will help curriculum designers develop quality curricula. In order to validate and ensure that the proposed model is more comprehensive, the model needs to be evaluated by various experts. In addition, other key curriculum components, including educational methods such as credit systems, need to be included.

\section{References}

[1] Hamam, H., Loucif, S., "Web-based Engine for Program Curriculum Designers," IEEE Transactions on Education, Vol. 52. no. 4, pp.563-571,2009.

[2] Thong, C.L., Yusmadi,Y. J., Rusli, A., Nor, H. A., Lee, K.C., "Identifying Difficulties in Curriculum Design for Institutions of Higher Learning in Malaysia," Proceedings of the Conference on Academic Development, Higher Education Conference, Nov 2-4, 2011.

[3] Christof L., Andrew L.R., Gilian D., John H., "A Maturity Model for Computing Education," Proceedings of the $9^{\text {th }}$ Australasian Conference on Computing Education and Computer Society, February 2007, Ballarat VIC., Australia.

[4] Jalote, P., "Needed: A Capability Maturity Model for Engineering Education," The Economic Times, India, 2003.

[5] Neuhauser, C., "A Maturity Model: Does it Provide a Path for Online Course Design?" The Journal of Interactive Online Learning. 2004. [Online] Available: http://whzhou.wordpress.com/2012/03/09/amaturity-model-does-it-provide-a-path-for-online-course-design/.

[6] Institute of Software Engineering, "The Capability Maturity Model: Guidelines for Improving the Software Process," Addision-Wesley Professional, 1995.

[7] Hafeez, M., "Application of SPICE (ISO/IEC 15504) in an Academic Environment," 1999. [Online] Available:http://citeseer.nj.nec.com/499756.html.

[8] Marshall, S. \& Mitchell, G., "E-Learning Process Maturity in The New Zealand Tertiary", Proceedings of the 22th Annual Conference of the Australian Society for Computers in Learning in Tertiary Education, December 9-11, 2005, Dunedin, New Zealand.

[9] Dennis, D., Minnie, Y. Yen, "Controlling Curriculum Redesign with a Process Improvement Model," Journal of Information Systems Education, Vol. 19:331-342.

[10] Marshall, S. \& Mitchell, G., "An e-Learning Maturity Model," Proceedings of the 19th Annual Conference of the Australian Society for Computers in Learning in Tertiary Education, December 8-11, 2002, Auckland, New Zealand, pp:1-10, 2002.

[11] COPPA, Programme Standards: Computing, Code of Practice for Programme Accreditation by the Malaysian Qualification Agency. Code of Practice for Programme Accreditation, pp. 12, 2008.

[12] Huang, S.H. and Tilley, S., "Towards a Documentation Maturity Model," Proceedings of the $21^{\text {st }}$ Annual International Conference on Documentation, October 12-15, 2003, San Francisco, California, USA., pp:93-99, 2003. 
International Journal of

Soft Computing And Software Engineering (JSCSE)

e-ISSN: 2251-7545

Vol.2,No.10, 2012

Published online: Oct 25, 2012

[13] Mandel, T., "Quality Technical Information: Paving the Way for Usable Print and Web-Interface Design," Journal of Computer Documentation, 26:118-125, 2002.

[14] Bloom, B. S., Engelhart, M.D., Hill, W.H. and Krathwohl, D.R., "Taxonomy of Educational Objectives: The Classification of Educational Goals, Handbook 1: Cognitive Domain. David Mc. Kay Company, Inc. New York, 1956, Pp.10-24, 1956.

[15] Krathwohl, D. R., Bloom, B.S. and Masia, B. B., "Taxonomy of Educational Objectives: The Classification of Educational Goals, Handbook II: Affective Domain,” David Mc. Kay Co. Inc., New York,1964 pp:3-12.

[16] Ng, M. L.Y. and Mustafa, R., "Higher Education and Human Capital Development in Malaysia and CLMV: Towards Strategic Partnerships and Alliance," Higher Education Monograph 17/2012. Chapter 3. Pp 39-70.

[17] MOHE, "National Higher Education Action Plan 2007-2010: Triggering Higher Education Transformation,” Kementerian Pengajian Malaysia, Malaysia, 2007, P. 51.

[18] Lewy, A., "Handbook of Curriculum Evaluation," $1^{\text {st }}$ Ed., UNESCO, New York, Longman, 1977, pp. 14-26.

[19] Green, L. W. and Kreuter, M., "Health Promotion Planning: An Educational and Environmental Approach," Polo Alto, Mayfield, 1991.

[20] Software Engineering, "Curriculum Guidelines for Undergraduate Degree Programs in Software Engineering," A Volume of the Computing Curricula Series August 23, 2004. [Online] Available: http://sites.computer.org/ccse/SE2004Volume.pdf.

[21] Alain A. and James W. M., "Guide to the Software Engineering Body of Knowledge," IEEE Computer Society Press, 2004, ISBN-13: 9780769523309, NY, USA, Pp.: 200.

[22] Bourque, P., Robert, F. Lavoie J.M., Lee, A. Trudel. S. and Lethbridge, T., "Guide to the Software Engineering Body of Knowledge: A Preliminary Mapping," Proceedings of the $10^{\text {th }}$ International Conference on Software Technology and Engineering Practice, October 6-8, 2002, Pittsburgh, PA., USA., 2002.

[23] Ng, M. L.Y., Tan, C., Rahman, S. A., Abduallah, N. A. and Kaur, S., "Higher Education and Human Capital Development in Malaysia and CLMV: Towards Strategic Partnerships and Alliance," Higher Education Monograph 17/2012. Chapter 5. Pp 145-157.

[24] Schmidt,W. H., "Why Schools Matter: A Cross-National Comparison of Curriculum and Learning,” San Francisco: Jossey-Bass, 2001, ISBN-13: 9780787956844, pages: 398, 2001.

[25] Squires, D. A., "Aligning and Balancing the Standard-Based Curriculum," Corwin Press, Thousand Oaks, Carlifornia, 2004, ISBN-13: 9780761939627, Pp. 57-59, 2004.

[26] Biggs, J., and Tang, C., "Constructive Alignment in Learning, Teaching and Assessment," Proceedings of the Conference on Engaging Students in Assessments, November 20-21, 2008, Adelaide SA. Australia.

[27] Paulk, M. C. "A History of the Capability Maturity Model for Software," SQP Vol. 12, No. 1/c 2009, pp.5-15. [Online] Available: https://secure.asq.org/perl/msg.pl?prvurl=/softwarequality/2009/12/process-management/a-history-of-the-capability-maturity-model-for- software.pdf.

[28] Crosby, P., "Quality is Free: The Art of Making Quality Certain," Mc-Graw-Hill, USA, 1979, P. 270, 1979.

[29] Murray, P., "Curriculum Development and Design," Second Edition, Allen \& Unwin, 1988.

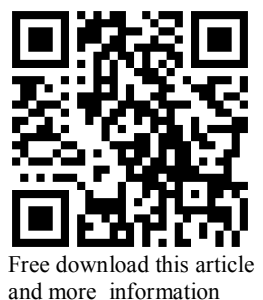

